\title{
Investigations on natural hazards which trigger technological disasters in Romania
}

\author{
A. Ozunu ${ }^{1}$, F. Senzaconi ${ }^{2}$, C. Botezan ${ }^{1}$, L. Ştefănescu ${ }^{1}$, E. Nour ${ }^{3}$, and C. Balcu ${ }^{4}$ \\ ${ }^{1}$ Babeş-Bolyai University, Faculty of Environmental Science and Engineering, Research Centre for Disaster Management, \\ Cluj-Napoca, Romania \\ ${ }^{2}$ General Inspectorate for Emergency Situations, Bucharest, Romania \\ ${ }^{3}$ Inspectorate for Emergency Situations "Gheorghe Pop de Bǎseşti” of Maramureş County, Baia-Mare, Romania \\ ${ }^{4}$ Inspectorate for Emergency Situations "Dimitrie Croitoru” of Sibiu County, Sibiu, Romania
}

Received: 5 January 2011 - Revised: 23 March 2011 - Accepted: 23 March 2011 - Published: 11 May 2011

\begin{abstract}
Romania faces the challenges of a developing country preparing to cope with disasters, be they natural or technological. The paper entails comprehensive research on technological accidents triggered by natural hazards (socalled Natech accidents). The research is based on a survey conducted by the competent authorities on the Seveso II Directive in 2009. This survey enabled the identification of Natech hazards and their correlation with the vulnerability of local communities and infrastructures. The Natech hazards were analyzed also in terms of their inclusion in the emergency planning process, starting from the current legislation. The results indicate that the number of incidents (including Natech events) has significantly decreased subsequent to the appropriate implementation of emergency plans and safety reports.
\end{abstract}

\section{Introduction}

Many recent studies show an increasing number of natural disasters which trigger technological disasters (also known as Natechs). Their significant negative consequences affect communities all over the world, especially those which are not prepared for such events. Although Natechs have been relatively rare events, the number of technological accidents is increasing. This is mainly because of the diversification of technologies and substances used, as well as the numerous possibilities of human error which can occur during their usage and operation. The negative consequences are amplifying, because there are more people living in large urban areas and there are more industrial facilities and more infrastruc-

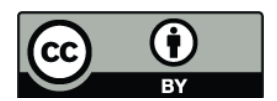

Correspondence to: A. Ozunu (alexandru.ozunu@ubbcluj.ro) ture which can be affected in case of a disaster. Therefore, there is growing awareness of the need for prevention and better preparedness for these high consequence-low probability events (Cruz and Okada, 2008a).

The characteristics of Natech disasters are difficult to study, as they are very complex, being in fact two joint events and quite rare, especially in Europe. Until recently, they have generally been studied as separate events, and not as joint disasters, as they are in fact. It is the conjoint natural disaster that makes the Natech situation so different and complex (Cruz and Krausmann, 2008). Therefore, there is little information available on the interactions and relations between natural disasters and technological accidents.

The consequences of these co-joint events are much more substantial for the health of people, environment and property than those posed by each hazard alone. Therefore, the risk management and emergency response planning require a specific management which can respond adequately to both the natural and technological disaster alike. A natural disaster will trigger most likely more than one technological accident almost simultaneously. The possibility of cascading disasters (domino effects) also exists as mitigation measures fail again and again and one release triggers another (Steinberg et al., 2008). In case of such an event, the utilities (water, power, and communications) will not function and the responders will be preoccupied with the intervention to the natural disaster (Cruz et al., 2004). Thus, a very efficient emergency response plan is necessary, which should include a wide range of measures for both natural and technological disasters. Also, the experts in the field of natural disaster risk reduction must work together with those involved in technological risk management. It is necessary to share knowledge in the field of both natural and technological risk assessment and management (Galderisi et al., 2008). 
Romanian territory in general and Romanian industrial sites in particular, are directly or indirectly exposed to a wide range of natural hazards, included in several major categories: geologic (earthquakes), geomorphic (landslides, mudflows, debris slide), atmospheric (heavy rainfalls and snows, blizzards, thunderstorms) and hydro (floods and flash-floods). Among these, the South-East Romanian earthquakes and the heavy rainfalls have a major importance causing many risk phenomena, in particular floods and landslides.

The hydrogeological hazards such as those mentioned above are known to have caused severe damages to vast areas of the five continents over the last few years, causing substantial economic losses in many countries, according to the statistics released at the end of the International Decade for Natural Disaster Reduction, proclaimed by the United Nations in 1990 (Miceli et al., 2008).

Recent studies performed in Romania provide us with relevant data on the landslide susceptibility in different parts of the country. For example, the mining perimeter in the Apuseni Mountains is subject to medium landslide susceptibility, and is thus an area for a potential Natech event occurrence. For the protection of the local communities and infrastructure, stabilization work is needed (Costan et al., 2010). In some cases, soil loss may be combined with extreme natural phenomena such as heavy rainfall and sudden snow melting to cause Natechs (Ştefănescu et al., 2011).

The Baia Mare accident in 2000 is a relevant example of such an event. On 30 January 2000, the Aurul Bozanta Mare tailings dam failed, releasing approximately 100000 cubic meters of contaminated water and tailings, containing 50 to 100 tones of cyanide, as well as heavy metals (copper). The genetic factors which produced the accident were a combination of dam design errors, inadequate operation of installations and the severe weather conditions (significant water layer caused by heavy rainfall $-301 \mathrm{sq}^{-1} \mathrm{~m}$ and snow melting $-60-70 \mathrm{~cm}$ ). The accident had profound negative effects on the aquatic ecosystem and underground aquifers, at a national and transboundary level. Following emergency interventions, the rupture was closed and the water release from the tailing dam was stopped on 3 February.

The Baia Mare experience resulted in major changes in the approach towards mine safety and response to accidents in general. It marked a turning point for a number of functionally related issues such as: waste disposal technology and mine management, accident prevention and management of environmental emergencies, the adequacy of current regulations to ensure public safety, and communication with the public (UNEP, 2000).

\section{Material and method}

The European Union, through the European Commission, Joint Research Centre and the Major Accident Hazards Bureau initiated a survey of natural hazard-induced chemical accidents also known as "Natechs" (natural-hazard triggered technological accidents), with the aim of obtaining relevant data on Natechs in European Union member states, which will lead to better designed and targeted Natech risk reduction strategies. This survey is of utmost importance, due to the fact that most countries do not have specific Natech risk and emergency management programs in place, although all have recognized the risks and challenges in preventing and preparing for this type of threat (Cruz and Okada, 2008b). From the 27 European Union Member States, only 14 responded to the survey. These countries are (in alphabetical order): Austria, Cyprus, Czech Republic, France, Germany, Italy, Lithuania, Luxemburg, the Netherlands, Poland, Romania, Slovakia, Sweden and the United Kingdom (Krausmann, 2010). Although the ratio is relatively small, their experience in Natech risk management is extensive, as these responding countries comprise more than $76 \%$ of the Seveso sites in Europe. All responding organisations belong to the public sector with 12 responses from competent authorities in the respective countries and 2 responses from academia, all operating at national level (Krausmann, 2010). These institutions have responsibilities in the field of environmental protection, civil protection, industry and economy, higher education and research. The answers were based on the professional expertise and experience of the respondents or on following up discussions with colleagues or meetings.

In Romania, the survey regarding Natechs took place at the beginning of 2009. The answers were provided by the Ministry of Administration and Interior, through the General Inspectorate for Emergency Situations (GIES), which is the main Romanian government institution dealing with natural and technological disasters, including Natech events. The purpose of this survey was to assess Natech risk management practices and awareness of Natechs, to identify case histories and lessons learned as well as needs and/or limitations in implementing Natech risk reduction strategies in European Union Member States. The layout of the questionnaire survey includes six main chapters:

- regulations for the prevention and mitigation of Natechs;

- Natech events data collection and retrieval;

- learning from Natechs: case histories;

- Natech awareness and risk reduction;

- identifying needs and limitations;

- background information.

The 24 questions comprised within the survey were both general and very specific, aimed at obtaining a general overview of the state of Natech risk reduction. The questions covered a wide range of topics, from legislative institutions and regulations to Natech risk reduction strategies or projects 


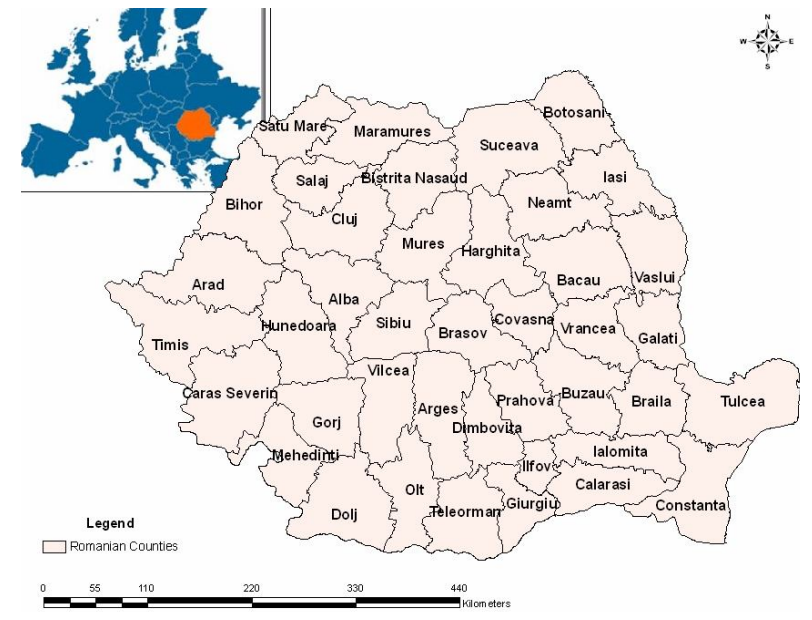

Fig. 1. Distribution of Romanian Counties.

in Romania. Depending on the information available, the questions could be answered in a more or less detailed way, contributing to the success of the survey.

The responses to the questionnaire were reported to the Joint Research Centre, which gathered and analysed the replies from the European Union Members States. Following the general analysis of the received EU questionnaire replies, the results of the study were disseminated, therefore becoming practical guidance for future Natech risk reduction strategies. The results of the EU Natech questionnaire survey are reported in Krausmann (2010).

From the legislative point of view, the existing EC legislation may be an appropriate framework to deal with this kind of events. Annex II of SEVESO II Directive states that scenarios have to include a summary of the triggering events, be their cause internal or external to the installation. In the SEVESO context, there is a need to clearly define the specific orientation and tools in order to consider this type of event when identifying and implementing prevention and mitigation measures.

In Romania, the legislation addressing natural hazards in order to prevent chemical accidents is quite extensive: G.D. $642 / 2005$ - Criteria for the classification of territorialadministrative units, public institutions and economic operators in terms of civil protection, depending on the specific types of hazards (referring to all types of natural hazards and including safety measures aimed at risk reduction); Law 107 of 1996 - Water law, with subsequent additions (dealing with floods and extreme weather phenomena and prohibiting the storage of chemicals in flood risk areas) and so on. Specific Natech risk reduction regulations are included in the territorial risk plan and the risk coverage and analysis plan, which address all types of natural disasters.

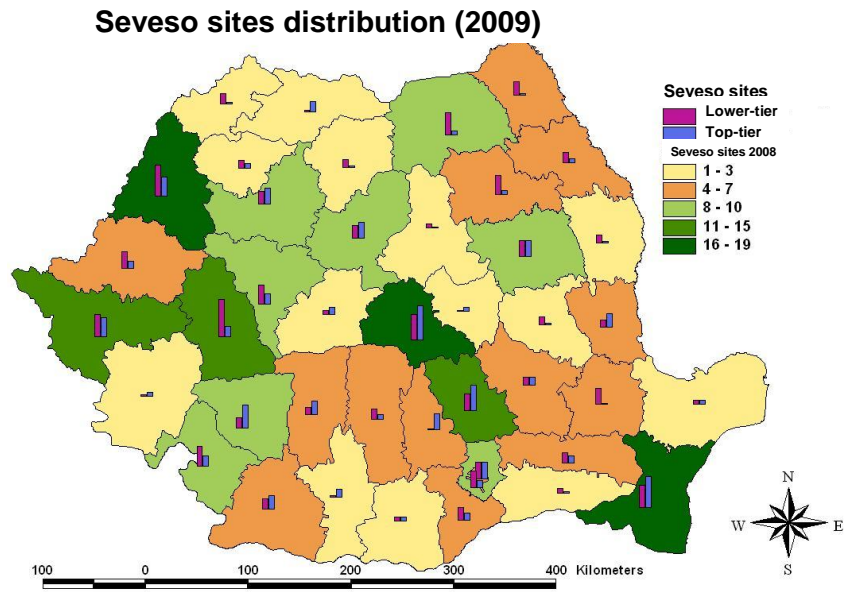

Fig. 2. Seveso sites distribution (2009).

The methodology applied in the development of this survey starts from the Seveso sites database and their distribution in Romania. The study considers the territory of Romania divided into 41 counties and the Ilfov county, where the capital - Bucharest is located, as it can be seen in Fig. 1. The distribution of the Seveso sites is approached in terms of counties and is correlated to the 2008 database. Then, the analysis of Natech events occurrence is performed using three sub-criteria: seismic zoning, floods and landslides susceptibility. These three specific sub-criteria assess the probability that a Natech event occurs in a Seveso site region by overlaying the Seveso sites distribution map and the natural hazards maps.

\section{Results and discussions}

In Romania, according to Government Decision no. 804/2007 regarding the control of major accidents involving dangerous substances (modified by G. D. no. 79/2009), at a national level there are 277 economic operators complying with the regulations in the Seveso Directive, of which 115 are top-tier sites and 162 are lower-tier sites. Their distribution in Romania is shown in Fig. 2.

During the last years, the total number of Seveso sites has increased. In 2006 there were 215 Seveso operators, while in 2009 , there were 277 . The number of top tier sites decreased slightly, from 145 in 2006 to 120 in 2009, while the number of lower tier sites increased, from 50 in 2006 to 170 in 2009. This represents a normal variation taking in consideration the expertise of competent authorities, changes in the legislative framework, and economical reasons. 


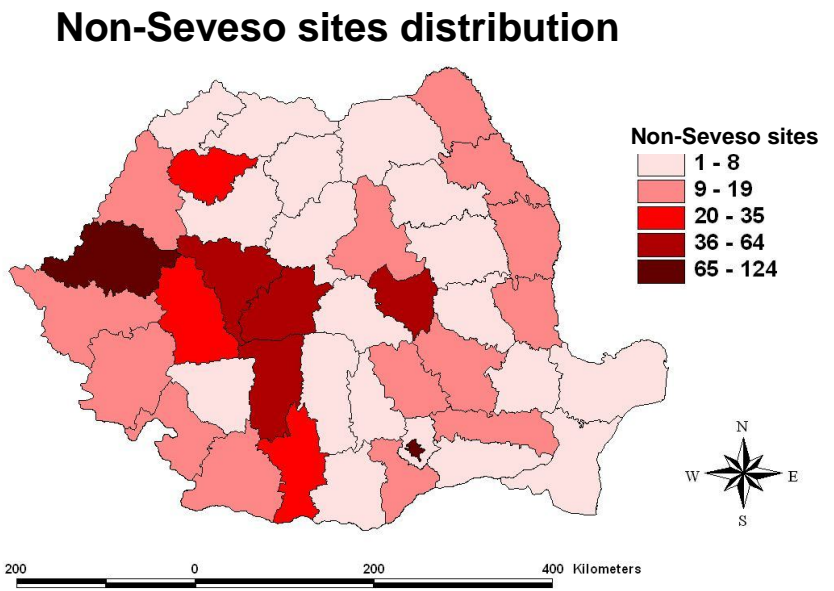

Fig. 3. Non-Seveso sites distribution (2009).

The non - Seveso sites are also very important, as they can be the place of major accidents occurrence, too. It can be observed from Fig. 3 that the distribution of the non-Seveso sites covers the entire surface of Romania. Most of the nonSeveso sites are located in Arad county (Western part of Romania) and Bucharest, followed by Alba, Sibiu, Vâlcea and Covasna county (central part of Romania). It must also be mentioned that all counties have at least one non-Seveso site, which can potentially contribute to the occurrence of a major industrial accident.

\subsection{Seismic zoning}

By overlapping the map of Seveso sites distribution and the seismic zoning, one may notice the major interest points, where a technological accident triggered by an earthquake can occur. The map in Fig. 4 indicates that within the area of $9^{\circ}$. MSK earthquake probability there are no significant industry operators using dangerous substances. Most of the major economical agents using dangerous substances are located in the area with a low probability of earthquake occurrence and within the area of $7^{\circ}$ MSK earthquake probability. Therefore, special attention must be paid to these sites and emergency plans considering a Natech scenario must be implemented.

\subsection{Flood risk}

The flood risk map (Fig. 5), elaborated by the Geography Institute of the Romanian Academy, overlapped the Seveso sites distribution sites, thus offering the opportunity to identify those areas prone to Natech events. As it can be observed from Fig. 5, flood risk areas cover a large surface of Romania, therefore increasing the Natech occurrence probability with flooding as a major cause. The map shows that the largest number of Seveso sites which could be affected by floods are situated in the Western and central part of Ro-

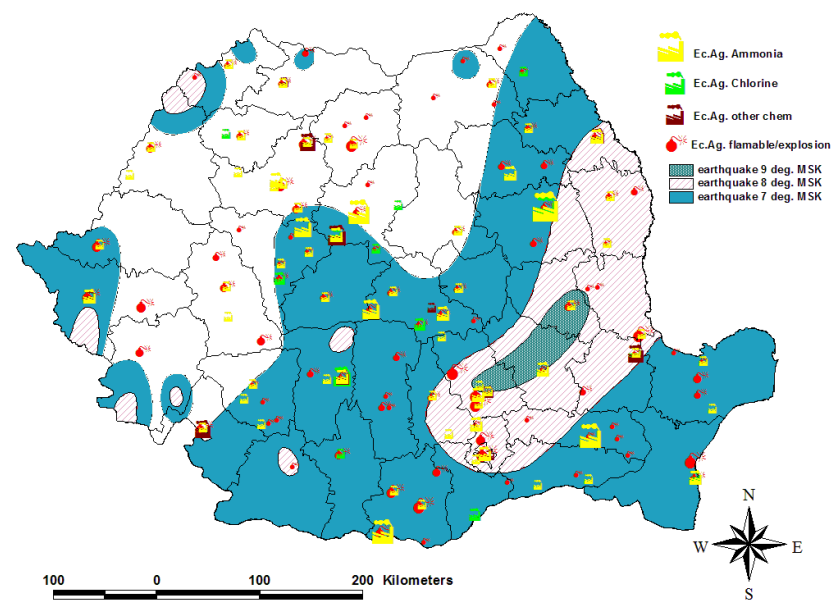

Fig. 4. Seismic zoning of Romania.

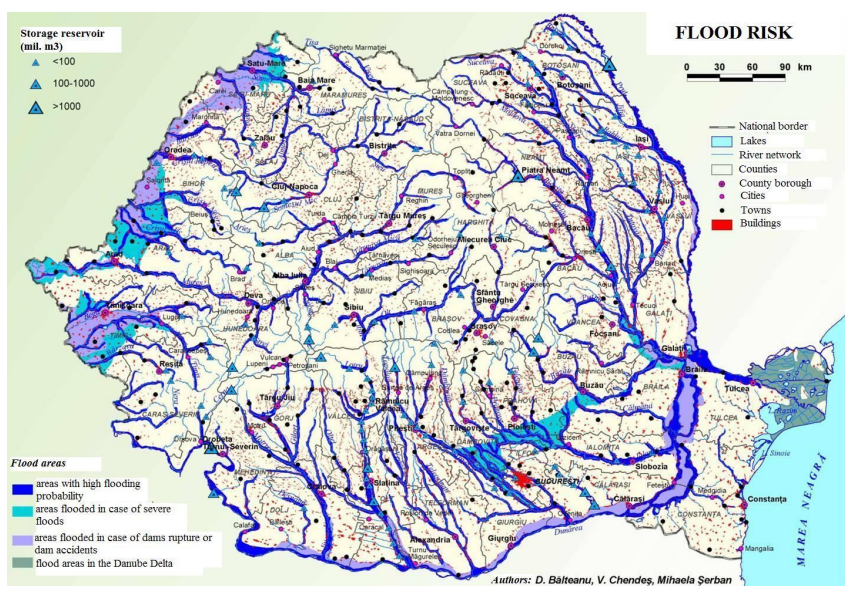

Fig. 5. Flood risk map of Romania (Bălteanu et al., 2007).

mania (Bihor and Braşov counties). Several major Seveso sites can also be found in Hunedoara, Alba and Mureş counties (central part of Romania). Fortunately, there are many counties which can be affected by floods and which do not have major Seveso Sites (Giurgiu, Olt - South, Caraş Severin, Caransebeş - South-West etc.).

\subsection{Landslide susceptibility}

The assessment of landslide susceptibility at a national level is regulated through Law no. 575 from 2001, regarding the approval of the National Land Use Planning Plan - Section $\mathrm{V}$ - Natural risk areas. This law is supported by a guide for the elaboration of landslide risk maps proposed by the Ministry of Local Public Administration. The guide provides a methodology which takes into consideration different factors: lithology, geomorphology, geological structure, hydrology, climate, hydrogeology, seismicity, forest cover and human activity. Mountains, hills and tablelands, which cover two thirds of the country's area, are particularly susceptible 


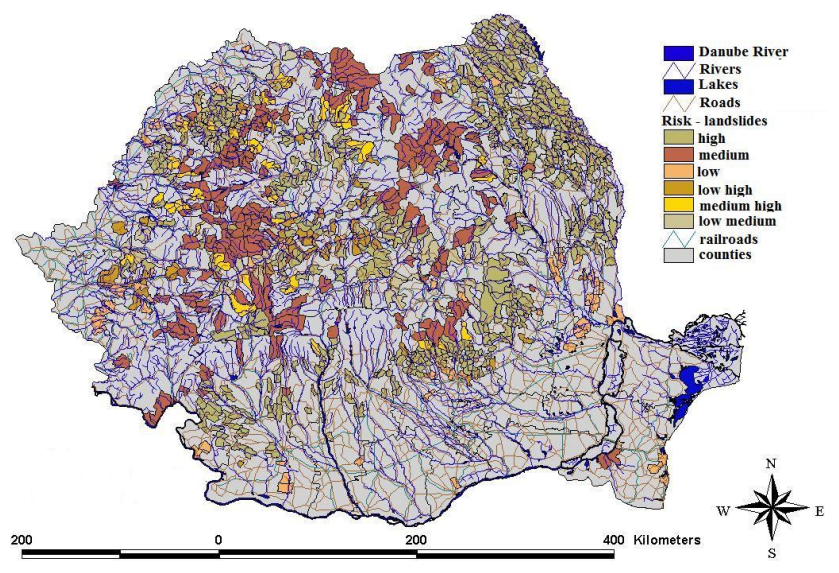

Fig. 6. Landslide risk map of Romania (Law no. 575/2010).

to landsliding, especially the hills and tablelands (Bălteanu et al., 2010). Overlapping the landslide susceptibility map and the Seveso sites distribution map, one can see that the county with the largest number of Seveso sites most likely to be affected by landslides is Brasov county, situated in the Central part of Romania. The 8-10 Seveso sites counties with a high probability of landslides occurrences lie in the SouthWestern and Eastern part of Romania, as it can be observed in Fig. 6.

Further studies are currently being developed on overlapping flood and landslide susceptibility maps with Seveso sites distribution map.

The Romanian legislation provides that the top-tier sites implement off-site and on-site emergency plans. Figure 7 indicates that there is a fair ratio between the existing on-site emergency plans and those which have been tested. Also, the number of on-site plans which include Natech scenarios has increased significantly from $30 \%$ in 2006 to $42 \%$ in 2009 , as shown in Fig. 8. This is mainly due to the increased awareness of the authorities and stakeholders regarding the risks induced by such events. Most of the existing off-site emergency plans are still being tested. The off-site plans including Natech scenarios ranged during the 2006-2009 period as follows: $17 \%$ in 2006, 28\% in 2007 and $25 \%$ in 2009.

An increasing number of Natech scenarios may also be noticed in the case of safety reports: although the number of safety reports decreased between 2006 and 2008, the number of safety reports including Natech scenarios increased from 46 in 2006 to 57 in 2008 (Table 1). In some cases (6 in 2007 and 8 in 2008), the safety reports included Natech scenarios for the first time after being updated, emphasizing the need to reconsider this type of event.

Unfortunately, despite the implemented on-site and offsite emergency plans, accidents still occur. Of the total industrial accidents, $50 \%$ were caused by human errors. Technical errors are the second main cause (24\% of all the cases). The other main causes are external factors $(16 \%)$ and uncontrolled chemical reactions (10\%), as shown in Fig. 9.

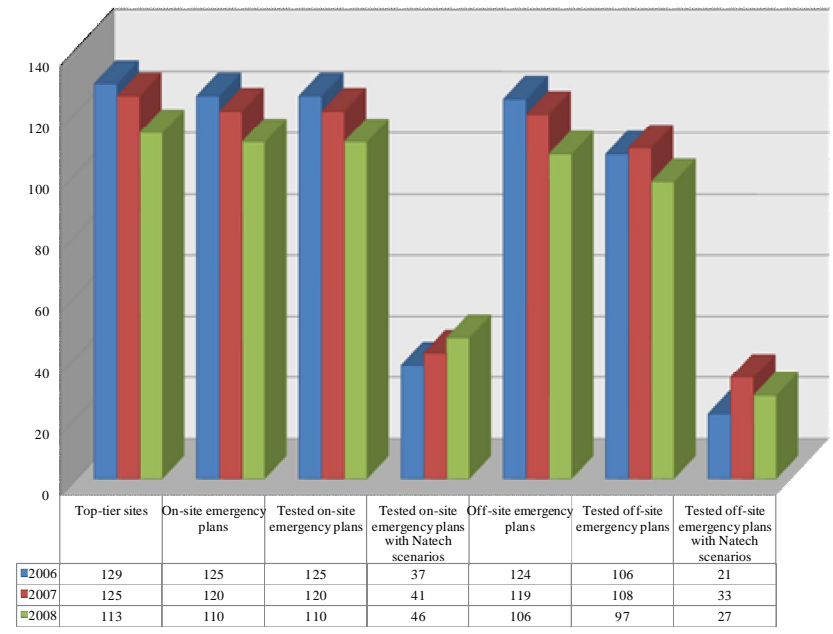

Fig. 7. State of emergency plans testing.

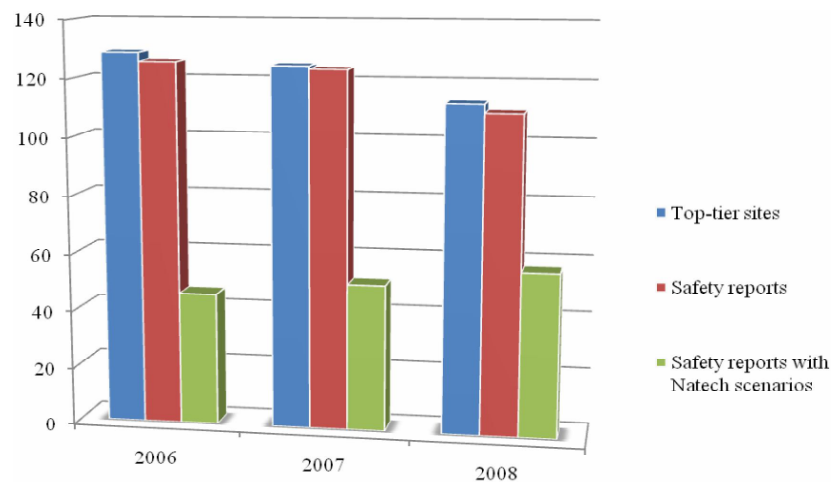

Fig. 8. Safety reports including Natech scenarios.

During the last years, most of the emergency response actions in the chemical, petrochemical and rubber industry (81) occurred in 2008, of which 73 were fires. In 2009, the number of emergency interventions decreased significantly. Still, most of these emergencies were caused by fires (Fig. 10).

The number of response actions to incidents caused by environmental contaminations with dangerous substances is similar: 67 in 2007, 193 in 2008 (the peak) and 33 in 2009. The peak reached in 2008 may be explained taking into consideration the legislative framework changes, the low degree of awareness of industry regarding the implementation of safety management systems, and the reorganisation of GIES (infusion of new personnel in the Seveso II field without expertise at the end of 2007). Fortunately, this situation improved during 2009 due to the concentrated effort of GIES in training personnel using the TAIEX instrument, EU funds and projects and coordinated seminars on Seveso II inspection, emergency planning and law enforcement. Thus, one can conclude that the implementation of emergency plans and safety reports was performed successfully. 
Table 1. The comparative situation of NaTech scenarios considered in Seveso sites risk analysis.

\begin{tabular}{lrrr}
\hline Type of Safety Report & 2006 & 2007 & 2008 \\
\hline Safety Reports (SR) & 126 & 124 & 110 \\
SR including Natech scenarios & 46 & 51 & 57 \\
Updated SR & 0 & 24 & 22 \\
Updated SR with Natech scenarios & 0 & 13 & 13 \\
SR where the Natech scenarios first & & & \\
occur after the update & 0 & 6 & 8 \\
\hline
\end{tabular}

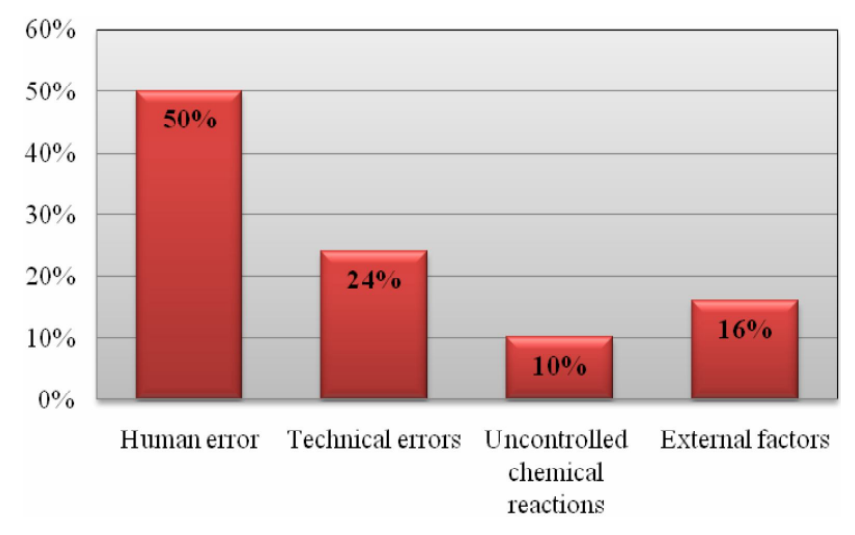

Fig. 9. Causes of industrial accidents.

\section{Conclusions}

In conclusion, the survey emphasises the need to raise awareness on the subject among industry, government, and the general public. The results have clearly highlighted the major role the low degree of awareness of industry regarding the implementation of safety management systems has played in the occurrence of unwanted incidents at Seveso sites. The challenges faced by industry and authorities alike include a better and a more integrated coordination between different scientific communities and responsible authorities.

In addition to the expertise of the representatives of the Environment, Health \& Safety Departments as well as of the Civil Protection experts dealing with Seveso, further contributions from civil/mechanical/earthquake engineering and from those responsible for planning and construction/building permitting of plants is considered necessary. Furthermore, natural risks have to be considered in the elaboration of risk assessment, in defining the appropriate prevention and mitigation measures, as well as in emergency planning, as Natechs represent a major threat to the population and environment. Therefore, assessing Natech probability occurrence and including this type of event in the emergency planning is a prerequisite for the social and economic development of every country.

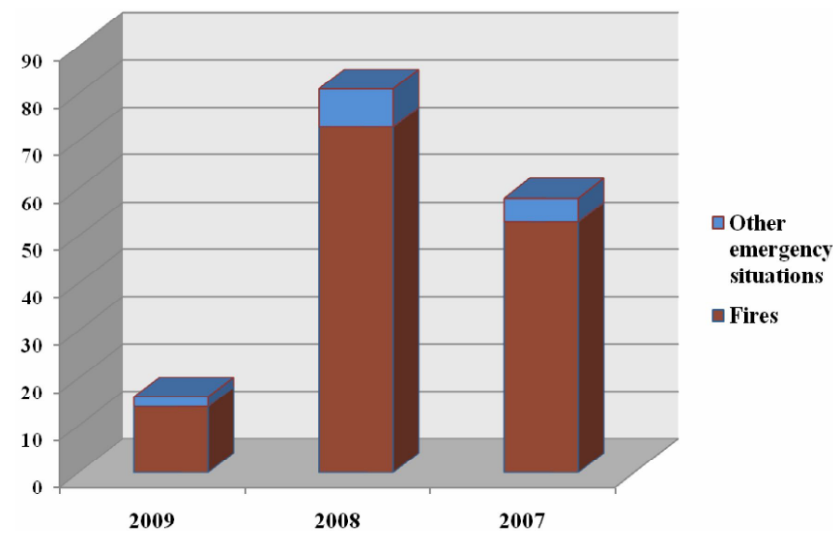

Fig. 10. Emergency response actions in the chemical, petrochemical and rubber industry.

According to the results of the survey, Romanian legislation addresses natural hazards in the regulations for chemical accident prevention and includes specific guidelines for Natech risk reduction. However, the occurrence of Natech disasters suggests that there are major gaps in managing Natech risks, translated into poor accident prevention. Therefore, the need to analyze this type of disaster in detail is urgent; so is the need to create specific Natech risk management regulations to be included in the current legislation.

The survey also concluded that the awareness of Natech risks is increasing within the competent authorities, but it is absent within industry. This problem could be solved by seminars and workshops involving stakeholders regarding the specificities of Natech risk and risk reduction measures. In addition, there should be clear and constant risk communication to the local community, thus increasing the population's preparedness for this type of event.

Another identified problem which requires special attention is the lack of specific methods, tools, technical guides and guidelines for Natech risk assessment, necessary for both competent authorities and for industry. Their elaboration is based on the lessons learned from past experience and should be stored in an electronic database, currently not existing in our country. Furthermore, the elaboration of Natech risk maps and scenarios would support an adequate and efficient emergency situation management.

Acknowledgements. The authors would like to thank the European Commission, Joint Research Centre and the Romanian Ministry of Administration and Interior for providing the data of the survey.

Edited by: E. Krausmann

Reviewed by: two anonymous referees 


\section{References}

Bălteanu, D., Sima, M., and Chendeş, V.: Natural and Technological Hazards related to Extreme Climatic Events in Romania, Climate change in South-Eastern European countries. Causes, impacts, solutions, Graz, Austria 26-27 March, 2007.

Bălteanu, D., Chendeş, V., Sima, M., and Enciu, P.: A countrywide spatial assessment of landslide susceptibility in Romania, Geomorphology, 124, 102-112, 2010.

Costan, C. S., Ştefănescu, L., Maloş, C. V., Ozunu, Al., and Vlad, Ş. N.: Landslide susceptibility in the Arieş Middle Basin - focus on Roşia Montană mining area, Advances in Environmental Sciences - International Journal of the Bioflux Society, AES Bioflux 2(1), 81-90, 2010.

Cruz, A. M. and Krausmann, E.: Results of the Workshop: Assessing and Managing Natechs (Natural-hazard triggered technological accidents), EUR Report $23288 \mathrm{EN}$, available at: http://www. preventionweb.net/files/9623_LBNA23288ENC002.pdf, 2008.

Cruz, A. M. and Okada, N.: Methodology for preliminary assessment of Natech risk in urban areas, Nat. Hazards, 46, 199-220, doi:10.1007/s11069-007-9207-1, 2008a.

Cruz, A. M. and Okada, N.: Consideration of natural hazards in the design and risk management of industrial facilities, Nat. Hazards, 44, 213-227, doi:10.1007/s11069-007-9118-1, 2008b.
Cruz, A. M., Steinberg, L., Arellano, A. L. V., Nordvik, J.-P., and Pisano, F.: State of the Art in Natech Risk Management, Joint Research Centre, European Commission, available at: http://www.unisdr.org/preventionweb/files/2631 FinalNatechStateofthe20Artcorrected.pdf, 2004.

Galderisi, A., Ceudech, A., and Pistucci, M.: A method for na-tech risk assessment as supporting tool for land use planning mitigation strategies, Nat. Hazards, 46, 221-241, doi:10.1007/s11069008-9224-8, 2008.

Krausmann, E.: Analysis of Natech risk reduction in EU Member States using a questionnaire survey, EUR Report $24661 \mathrm{EN}$, European Union, 2010.

Miceli, R., Sotgiu, I., and Settanni, M.: Disaster preparedness and perception of flood risk: A study in an alpine valley in Italy, J. Environ. Psychol., 28, 164-173, 2008.

Steinberg, L. J., Sengul, H., and Cruz, A. M.: Natech risk and management: an assessment of the state of the art, Nat. Hazards, 46, 143-152, doi:10.1007/s11069-007-9205-3, 2008.

Ştefănescu L., Constantin V., Surd V., Ozunu Al., and Vlad Ş.N.: Assessment of soil erosion potential by the USLE method in Roşia Montanǎ mining area and associated NATECH events, Carpath. Jo. Earth Env., 6(1), 35-42, 2011.

UNEP, Dissection of an Accident: Lessons Learned and Follow up Actions from Baia Mare, Industry and Environment, 23, 64-65, 2000. 